\title{
"Melhor idade"? Será mesmo? A velhice segundo idosas participantes de um grupo de atividade física
}

\author{
"Best age"? Really? Old age according to elderly women participating in a physical \\ activity group
}

\section{AUTORES \\ Joamara de Oliveira Pimentel ${ }^{1}$ (D) \\ Mathias Roberto Loch² \\ 1 Universidade Estadual de Londrina, Programa de Pós-Graduação em Saúde Coletiva, Londrina, Paraná, Brasil. \\ 2 Universidade Estadual de Londrina. \\ Departamento de Saúde Coletiva, Programa de Pós Graduação em Saúde Coletiva, Londrina, Paraná, Brasil}

\section{CONTATO}

Joamara de Oliveira Pimentel

joamarauel@hotmail.com

Rua Emiliano Perneta, 246, Vivendas do

Arvoredo, Londrina, Paraná, Brasil.

CEP: 86047-565.

DOI

$10.12820 /$ rbafs. $25 \mathrm{e} 0140$

\begin{abstract}
RESUMO
O objetivo deste estudo foi verificar percepções de idosas participantes de um grupo de práticas corporais/atividade física (PCAF) sobre a vida na velhice, sobre significados da aposentadoria e sobre o papel deste grupo nas suas vidas. Foi utilizada abordagem qualitativa, seguindo roteiro semiestruturado para entrevista com 12 idosas de um grupo de PCAF de uma Unidade Básica de Saúde em uma cidade do Paraná. Elementos da técnica de análise de conteúdo foram utilizados na análise dos dados. Observou-se que na percepção das entrevistadas, na categoria "A vida na "melhor idade" há uma ambiguidade de sentimentos e percepções: queda na qualidade de vida devido a doenças, solidão e falta de autonomia, mas os provimentos da aposentadoria permitiram autonomia financeira. $\mathrm{Na}$ categoria "Expectativas quanto à aposentadoria", referiram que a realidade foi diferente do que imaginavam que seria, principalmente pela piora da condição física e clínica e pela necessidade de realizarem cuidados a outros membros da família. Na categoria "Mudanças percebidas na vida após a participação no grupo de PCAF", relataram melhora do quadro clínico de saúde, redução de dores corporais, melhoras no sono, além de pertencimento ao grupo e alegria no viver. Os achados deste estudo podem ser úteis para a compreensão mais aprofundada sobre os múltiplos significados da velhice, fugindo-se de concepções simplistas que buscam atribuir a esta fase da vida um sentido de "melhor" ou "pior" que outras fases da vida.
\end{abstract}

Palavras-chave: Atenção primária à saúde; Atividade motora; Saúde da mulher; Envelhecimento.

\section{ABSTRACT}

The aim of this study was toverify the perceptions of elderly women participating in a group of body practices/physical activity (BPPA) about life in old age, abput the meanings of retirement and about the role of this group in their lives. A qualitative approach was used, following a semi-structured script for interviewing 12 elderly women from a BPPA group in a Basic Health Unit in a city in Parana. Elements of the contente analysis tecnique were used in the data analysis. It was observed that in the perception of the interviewees, in the category "Life in the 'best age" there is na ambiguity of feelings and perceptions: drop in quality of life due to illness, loneliness and lack of autonomy, but the retirement provisions allowed financial autonomy. In the category "Expectations regardins retirement", they referred that the reality was diferente from what they imagined it would be, mainly due to the worsening of the physical and clinical condition and the need to provide care to other family members. In the category "Perceived changes in life after participating in the BPPA group", they reported na improvement in the clinical health condition, redution of body pain, improvements in sleep in addition to belonging to the group and joy in living. The findings of this study may be useful for a deeper understanding of the multiple meanings of old age, avoiding simplistic conceptions that seek to atribute to this phase of life a sense of better or worse than other moments in the life cycle.

Keywords: Primary health care; Motor activity; Women's health. aging. mento marcante, levando a pessoa a se rever enquanto indivíduo, especialmente por encontrar-se em situação ambígua: por um lado podendo passar por certa desvalorização social, inclusive pela perda da identificação com a profissão e, ao mesmo tempo, sendo "alvo" de campanhas que incentivam o consumo e que se apegam à ideia de que a velhice pode ser a "melhor idade". No Brasil, a população idosa vem crescendo, sendo que em 2017, esta população era de cerca de 30 milhões de 
pessoas e destas, $56 \%$ eram mulheres ${ }^{2}$.

A velhice e o processo de aposentadoria ocorrem de maneiras distintas entre homens e mulheres, considerando características biológicas, socioculturais, educacionais, entre outras que transpassam a singularidade desses indivíduos, portanto, não se pode determinar um critério padrão para a vivência da velhice ${ }^{3,4}$. Logo, é indispensável pensar questões de gênero na elaboração das políticas públicas ${ }^{5,6}$.

Uma das ações estratégicas para melhorar condições de saúde da população idosa está relacionada à promoção de práticas corporais/atividade física $(\mathrm{PCAF})^{6-8}$, inclusive em função da relação destas práticas com indicadores de saúde ${ }^{9-11}$. A participação das mulheres idosas tem sido predominante em grupos de PCAF oferecidos em Unidades Básicas de Saúde ${ }^{12,13}$, que têm potencialmente um importante papel no contexto brasileiro da promoção da atividade física ${ }^{14-16}$. Esta maior participação feminina está provavelmente relacionada ao fato de as mulheres terem, em geral, um maior autocuidado, e de se aposentarem, em média, com idade inferior a dos homens. Outros pontos a serem destacados dizem respeito às atividades serem oferecidas normalmente em horário comercial, além do tipo de atividade que costuma ser ofertada, que pode ser mais atrativa para mulheres do que para homens ${ }^{17}$.

A partir principalmente do final do século passado foram elaboradas políticas públicas ${ }^{6-8}$ que dialogam com o contexto apresentado. Destacamos ainda que as mulheres que atualmente são idosas envelheceram em um contexto de significativas transformações socioculturais e econômicas e, nesse sentido, alcançar uma melhor compreensão sobre aspectos da vida destas mulheres é importante inclusive para aprimorar o planejamento dos serviços de saúde.

O objetivo deste estudo foi verificar percepções de idosas participantes de um grupo de PCAF sobre a vida na velhice, sobre o papel deste grupo nas suas vidas e sobre expectativas e realidades da aposentadoria.

\section{Métodos}

Foi realizada uma pesquisa qualitativa explorando algumas percepções das entrevistadas, buscando um melhor entendimento sobre os significados que alimentam as opiniões e as visões de mundo ${ }^{18}$.

Foram selecionadas intencionalmente mulheres participantes de um grupo de PCAF de uma UBS, na qual atuava a Residência Multiprofissional em Saúde da Mulher (RMSM) da Universidade Estadual de Lon- drina (UEL), em Cambé, região Norte do Paraná, que contava com a participação das seguintes áreas: Educação física, Enfermagem, Farmácia, Nutrição e Psicologia, sendo considerados estes critérios de inclusão: ter 60 anos ou mais, frequência mínima de 50\% nas atividades do grupo no ano de 2015 (março a dezembro), ser mãe e não morar sozinha. Participavam do grupo 26 pessoas (22 mulheres). Destas, 13 eram elegíveis pelos critérios de inclusão. Houve uma recusa, ficando assim a amostra final com 12 idosas. Destas, cinco iniciaram a participação no grupo em 2015 e sete antes de 2015, mas não temos dados destas últimas sobre quanto tempo antes de 2015 iniciaram sua participação.

O grupo de PCAF acontecia três vezes por semana. Os participantes iam até a UBS para mensuração da pressão arterial e depois se dirigiam até um ginásio de esportes próximo, com a residente de educação física e ao menos um agente comunitário de saúde. As atividades incluíam aquecimento articular e muscular, caminhada de 30 minutos, exercícios de resistência e força muscular, alongamento e relaxamento, com duração total de 90 minutos (contando do momento em que chegavam à UBS).

$\mathrm{Na}$ coleta de dados foi utilizada entrevista semiestruturada, aplicada individualmente. Esta técnica responde especialmente objetivos exploratórios sendo empregada para detalhar temas e elaborações mais acertadas das concepções relacionadas ao estudo ${ }^{19} \mathrm{e}$ tende a favorecer a análise de perspectivas afetivas e valores, que designam conceitos pessoais de comportamentos e atitudes. As entrevistas foram gravadas com aparelho celular, posteriormente transcritas manualmente (digitadas), sem utilização de software específico e apagadas após a transcrição.

A construção do instrumento de coleta teve a colaboração dos participantes do grupo de pesquisa em Educação Física e Saúde Coletiva da UEL, que contava com a participação de alunos de graduação em Educação Física, alunos da RMSM e Saúde da Família e de pós-graduandos do Programa de Saúde Coletiva, além de professores com experiência em ambas as áreas. A partir da primeira versão do instrumento, foi realizada uma entrevista piloto com uma participante do grupo que não era elegível para o estudo. Após isto, o instrumento foi reformulado e outras duas entrevistas piloto foram realizadas. Todas as entrevistas foram conduzidas pela pesquisadora principal, que tinha experiência prévia em estudos qualitativos, em função da participação em grupo de estudos que utilizava métodos qualitativos. 
No início da entrevista eram explicados os objetivos do trabalho. Todas assinaram o Termo de Consentimento Livre e Esclarecido. Buscando preservar a identidade das entrevistadas, estas foram identificadas como "Lua" e o respectivo número da entrevista.

Após estes esclarecimentos, as entrevistas foram iniciadas (em agosto de 2016) com perguntas relativas à caracterização das participantes e após, seguiu-se o seguinte roteiro: a) Participar do grupo de PCAF mudou alguma coisa na vida da senhora?; c) A senhora está satisfeita com sua vida atualmente?; d) Quando falam que a senhora está na 'melhor idade', o que a senhora acha disto?. Em um segundo momento (julho de 2017), com o objetivo de aprofundar algumas questões, entramos em contato novamente com as entrevistadas. Todas concordaram em participar de uma nova entrevista, sobre as condições de saúde e convívio social após cinco meses que a residência havia encerrado suas atividades naquela UBS e, consequentemente o grupo de PCAF, e sobre expectativas e realidades da aposentadoria.

$\mathrm{Na}$ análise dos dados utilizaram-se elementos da análise de conteúdo, buscando obter a descrição dos componentes que fazem parte do estudo, extrair sua significação, reconhecer o essencial e selecioná-lo em torno das ideias principais sobre o tema ${ }^{20}$.

Foram consideradas três categorias de análise, definidas após a transcrição: "A vida na 'melhor idade", "Expectativas quanto à aposentadoria" e "Mudanças percebidas na vida após participação no grupo de PCAF".

$\mathrm{Na}$ apresentação dos resultados, mantivemos a ma- neira original de fala das participantes, ajustando apenas a concordância verbal.

Este estudo foi aprovado pelo Comitê de Ética em Pesquisa da UEL (protocolo 54969216.6.0000.5231).

\section{Resultados}

A idade das participantes variou entre 61 e 81 anos. A maioria referiu menos de quatro anos de estudo e somente uma concluiu o ensino médio. Apenas duas nunca tiveram trabalho remunerado. Seis eram casadas, cinco viúvas e uma divorciada. Maiores detalhes podem ser observados no Quadro 1.

Em relação à satisfação com a vida atual, foram observadas falas indicando bom nível de satisfação:

Lua 7: "Tồ sim [na "melhor idade"], porque pra mim aqui 'tá' bem melhor agora do que no sítio. Não pago aluguel, e pra mim 'tá' sendo bom."

Lua 11: "Tồ' [na "melhor idade"]. Antes eu não gostava de festa de aniversário. Depois dos 60 anos eu quero festa todo ano, que agora élucro."

Outras idosas, apesar de considerarem que estão na "melhor idade", referiram sentimentos como tristeza por mortes na família:

Lua 2: "Tô" [na "melhor idade"], contudo, a falta do meu esposo e do meu filho eu sinto muito."

Lua 6: "Sim [está na "melhor idade"], só 'tồ triste pela perda (...). Eu achei que ele [marido falecido há me-

Quadro 1 - Características sociodemográficas das participantes do estudo. Cambé, Paraná 2016.

\begin{tabular}{lcccccc}
\hline Identificação & Idade & Escolaridade & Estado Civil & PCAF & DCNT & Trabalhava* \\
\hline L1 & 64 & Fundamental incompleto & Casada & Grupo UBS 3x semana & Artrose \\
L2 & 81 & Fundamental incompleto & Viúva & Grupo UBS 3x semana & Sín \\
L3 & 66 & Médio completo & Viúva & $\begin{array}{c}\text { Grupo UBS 3x semana; } \\
\text { hidroginástica 2x semana. }\end{array}$ & Hipotireoidismo & Sim \\
L4 & 64 & Fundamental incompleto & Casada & $\begin{array}{c}\text { Grupo UBS 3x semana; } \\
\text { hidroginástica 2x semana. }\end{array}$ & $\begin{array}{c}\text { HAS, Hipercolesterolemia, } \\
\text { hipotireoidismo }\end{array}$ \\
L5 & 63 & Fundamental incompleto & Viúva & Grupo UBS 3x semana; & Diabetes \\
L6 & 68 & Não estudou & Casada & Grupo UBS 3x semana & Reumatismo \\
L7 & 70 & Fundamental incompleto & Viúva & Grupo UBS 3x semana & HAS, DM \\
L8 & 65 & Fundamental incompleto & Divorciada & Grupo UBS 3x semana & HAS \\
L9 & 65 & Fundamental incompleto & Casada & Grupo UBS 3x semana & HAS \\
L10 & 61 & Fundamental incompleto & Viúva & Grupo UBS 3x semana; & HAS, hipercolesterolemia \\
L11 & 62 & Fundamental incompleto & Casada & Grupo UBS 3x semana & DM, arritmia cardíaca, HAS, & Sim \\
L12 & 66 & Fundamental incompleto & Casada & Grupo UBS 3x semana & HAS, arritmia cardíaca & Sim \\
\hline
\end{tabular}

*Tinham trabalho remunerado antes dos 60 anos. DCNT = doenças crônicas não transmissíveis; HAS = hipertensão arterial sistêmica; DM = diabetes mellitus. 
nos de um ano] ia viver comigo até o resto da vida. Um cuidando do outro até o final"

Outras entrevistadas consideram que estão na "melhor idade", por questões de conforto, recurso financeiro da aposentadoria e autonomia:

Lua 1: "Agora a gente tem mais conforto que quando era jovem. Antes não podia sair, agora a gente vai pra onde a gente quer."

Lua 2: "Tive muitos problemas quando era mais nova. Toda a vida bastante doente, muita pobreza. Então foi uma vida assim muito difícil, agora não."

As que consideraram que não estavam na "melhor idade", utilizaram como argumentos as doenças, falta de força física e de autonomia - tanto física quanto financeira - e a solidão:

Lua 7: "A pessoa mais nova tem mais força pra trabalhar. Com essa idade que eu 'tô' já é diferente. Você não pode fazer serviço pesado."

Lua 8: "O povo fala: 'ah a pessoa de idade é bom porque prioridade disso, daquilo, não paga ônibus'. Eu tinha uma vida muito melhor quando eu trabalhava e pagava ônibus. Chegava domingo tinha aquela alegria, tinha dinheiro. Hoje não tenho, só converso. Mas quando eu 'tô' em casa, 'tô' sozinha, porque meu filho mora aqui mas trabalha, chega já quase de noite. O dia que eu me sinto melhor é o dia que meu irmão aparece. Se não tem ninguém pra conversar, você guarda aquilo só pra você, aquilo não faz bem. Eu me sinto mal."

Lua 12: "Acho que é a pior [idade], porque cada vez vai ficando mais velha ai vai ficando doente."

Uma das entrevistadas relatou que "melhor idade" é a da adolescência, quando as responsabilidades eram menores e menciona ainda que não consegue mais fazer as mesmas atividades que fazia anteriormente, em função de dores corporais e que antes realizava trabalhos "pesados", com muito esforço físico. Porém, a idosa não associa o tipo de trabalho exercido anteriormente com as dores que sente atualmente:

Lua 9: "A melhor idade é aquela da adolescência, que a gente não pensa nada, não tem preocupação. Até meus 60 anos eu não tinha problema nenhum, ai aparece uma dor na coluna, uma 'coisinha' ali, outra lá. Fazer serviço de homem eu fazia, de pegar muito peso, fazer coisas que eu fiz a vida toda e hoje não posso fazer."

Em relação às expectativas sobre a aposentadoria, algumas relataram imaginar que seria bom, mas que a realidade tem sido diferente, por precisarem assumir cuidados com integrantes da família:

Lua 2: "Eu pensava que ia passear bastante. Queria arrumar um trabalho voluntário. Mas não deu, começaram as doenças em casa. O marido cada vez pior, depois minha mãe ficou doente. Ai não deu para trabalhar como voluntária."

Lua 5: "Sonhava em viajar. Ai depois aconteceu do pai falecer, a mãe veio morar com a gente. Ai não pude sair mais"

Outras idosas relataram que não tinham expectativas quanto à aposentadoria, pois não pensavam no assunto ou pensavam que não viveriam o suficiente para se aposentar:

Lua 3: "Eu não pensava que eu ia chegar à aposentadoria, achava que morreria antes. Não tinha expectativa de viver 67 anos como 'tô' vivendo."

Lua 8: "Nunca pensei, nunca me preocupei (...). Se tivesse trabalhando e não deixasse faltar nada dentro de casa, para mim 'tava' bom. Só pensava em trabalbar e sustentar meus fllhos."

Quanto aos pontos positivos de estar aposentada, foram citadas a questão da segurança financeira e o não compromisso com os horários de trabalho:

Lua 3: "Antes eu esquentava a cabeça, fazia muito crochê para vender. É um dinheiro que 'tá' todo mês na conta da gente [a aposentadoria], então faz muita diferença."

Lua 11: "Financeiramente é bom, para gente não ter que depender dos outros. Não tem igual ser o dinheiro da gente." Lua 12: "Ah foi bom, descansei mais. Não fica com aquele pensamento de todo dia sair cedo para trabalhar."

Os pontos negativos da aposentadoria evidenciados foram relacionados à falta de convivência com colegas de trabalho, às doenças, às dores corporais, ao aumento do peso, da ansiedade, ao estresse causado pela necessidade de cuidar dos membros da família e na piora da condição física:

Lua 5: "Eu sinto que eu 'tô'ficando esquecida. Até então eu era ativa. Nossa, eu entrava no ônibus assim que ponba- 
va' a perna lá já 'tava' dentro do ônibus. A hora de descer colocava a perna lá e pulava no chão. E ai depois [que parou de trabalhar] eu fui pular do ônibus, coloquei o pé lá e pulei, mas deu um 'baque' que quase que me travou tudo, foi uma dor que eu sai andando assim travada"

Lua 10: "Não via a hora de sair minha aposentadoria. Ai eu fiquei ai dentro de casa. Então a minha vida mudou muito. Engordei, sou hipertensa, tenho colesterol. fiquei com estresse por causa da ansiedade. Hoje cuido de neto, é estressante."

Lua 12: "Para saúde não foi bom. Quando eu trabalhava parece que eu não vivia doente. Aumentou o problema do coração, arritmia, minha pressão subiu. A gente fica lembrando das colegas."

Quanto às mudanças percebidas na vida após a participação no grupo de PCAF, algumas falas demonstraram melhoras no ânimo, conquista de novas amizades e melhor interação social:

Lua 1: "Eu tenho mais ânimo pra fazer as coisas, a gente "pega' amizade com os colegas"

Lua 11: "Porque [antes de iniciar no grupo], eu vivia numa tristeza. Ab, sei lá, parece que eu até queria morrer, [risos]. Agora não vejo a hora de chegar o dia de eu ir pra gente encontrar pessoas, conversar e caminhar, fazer o exercicio."

Outras referiram-se às mudanças em condições clínicas de saúde, de condicionamento físico e melhora em aspectos funcionais:

Lua 4: "Fiquei menos estressada, melhorou o colesterol, 'triglicéris' alto que eu tenho. Acho que até na tireoide ajudou."

Lua 6: "Mudou meu estilo de vida. Eu não tenho aquela moleza, eu saio, eu tenho disposição. Isso foi [devido à] a caminhada, os exercício, e outra coisa que eu não conseguia é abotoar meu sutiã. Meu braço não ia pra trás. [Agora] ele vai, eu tiro, eu abotoo, não sinto dor. Eu não conseguia fazer isso daqui ó [colocar o braço para trás e deixar a mão na altura do fecho do sutiã] pra trás."

Lua 10: "O remédio de colesterol era todo dia, eu tirei meu remédio. A caminhada eu sinto que faz muito bem pra gente. Eu vou lá desanimada, quando eu volto, volto outra pessoa, volto animada.".

Também foram observadas falas referentes à diminui- ção de dores corporais, melhora do sono e da memória:

Lua 7: "Eu sentia muitas dores no joelho. Eu até pensava: vou fazer caminhada e vai prejudicar. Mas não prejudicou. Eu 'tô' caminhando bem agora."

Lua 10: "Minha dor na perna foi embora. E outra: é bom pra memória também, sabe que 'tâ' sendo bom, 'tô' prestando atenção (...), dá mais é sono pra gente dormir."

\section{Discussão}

Viver a velhice para as entrevistadas neste estudo tem sido uma experiência com ambiguidade de sentimentos e percepções. Alguns pontos negativos destacados por elas foram: declínio na qualidade de vida em consequência de doenças, solidão e falta de autonomia, enquanto os positivos foram autonomia financeira proveniente da aposentadoria e, em relação à participação no grupo de PCAF, os discursos evidenciaram melhora no quadro clínico de saúde, além do pertencimento ao grupo e alegria no viver.

A Política Nacional de Atenção Integral à Saúde da Mulher ${ }^{6}$ expõe a necessidade de estratégias que diminuam morbimortalidades por causas evitáveis. Concordando com a Política Nacional de Promoção da Saú$\mathrm{de}^{8}$, tais políticas mostram que a formação de grupos para pessoas idosas torna-se espaço favorável e singular para a formação de redes de apoio, permitindo observar potencialidades, auxiliar em vulnerabilidades, elevar o empoderamento e a autoestima dos participantes, desenvolvendo habilidades individuais e coletivas, efetivando a intercessão à saúde e à vida, como observado na fala das idosas.

As imagens socialmente construídas a respeito da velhice são muitas vezes associadas à dependência, dificuldades funcionais e doenças, como atributos normais e obrigatórios desta fase da vida. No entanto, o envelhecimento é um aspecto natural da vida, e a saúde da pessoa idosa depende de fatores ligados às circunstâncias em que a pessoa viveu, os aspectos econômicos, sociais, culturais, comportamentais dentre outros que vão além do fato de terem ou não saúde ${ }^{21}$.

Mesmo que muitas expectativas em relação à aposentadoria tenham sido frustradas para algumas das entrevistadas, por conta de doenças e cuidados com pessoas da família, após a aposentadoria elas puderam participar de atividades que provavelmente não teriam conseguido antes desse período, como a própria participação no grupo de PCAF. Estes resultados são coerentes com um estudo sobre o imaginário e a subje- 
tividade na aposentadoria feminina ${ }^{1}$, em que a aposentadoria possibilitou experiências que não eram viáveis antes, mas que também as "capturou" para o cuidado com integrantes da família. Outro estudo que traz resultados semelhantes em relação ao papel da mulher na assistência aos familiares é sobre a prática de Ioga em mulheres adultas e idosas ${ }^{22}$ que por conta dessa fase, intensificaram tais cuidados limitando o tempo de dedicação a si mesmas. Essa situação revela o quanto ser mulher em nossa sociedade está fortemente relacionado ao papel histórico e socialmente construído do cuidar.

Assim, uma reflexão importante diz respeito ao planejamento ou preparação para a fase da aposentadoria, para que o confronto entre o imaginário e a realidade seja minimizado reduzindo possíveis frustrações, procurando entender as peculiaridades da vida nessa fase. Percebemos que havia falta de perspectiva de algumas entrevistadas quanto à aposentadoria, quando estas relataram não refletir anteriormente sobre o tema, inclusive porque algumas achavam que morreriam antes, pois muitos dos seus pais não chegaram à velhice.

Um estudo que investigou o acesso aos programas públicos de atividade física no Brasil evidenciou que a população idosa é a que mais conhece tais programas ${ }^{23}$. Entretanto, grande parte da população pouco sabe a respeito das PCAF oferecidas na saúde pública e, das que conhecem, poucas são as que participam de tais atividades. Neste contexto, é importante reforçar a importância da Atenção Básica, bem como a inserção da Educação Física neste cenário. As PCAF como tema de saúde pública, progrediram substancialmente nos últimos anos, porém ainda há de se construir um caminho em que fique claro para gestores, profissionais de saúde e população em geral que o acesso às PCAF deve ser um direito e não um privilégio. Neste sentido, o SUS tem um papel fundamental para garantir que mais pessoas tenham acesso as PCAF e compreendendo-as como algo integrado às outras ações e estratégias dos serviços de saúde ${ }^{16}$.

Pertencer ao grupo de PCAF agregou funcionalidade e entusiasmo à vida, tanto na melhora das condições de saúde relacionados às doenças crônicas e autonomia funcional, redução de dores corporais e de uso de medicamentos, melhora na qualidade do sono e da disposição, como no aspecto social, minimizando a sensação de solidão, melhorando e aumentando a interação com pessoas em condições semelhantes. No entanto, vale mencionar que estas melhoras aconteceram na percep- ção das mulheres entrevistadas, o que não quer dizer que necessariamente todas as pessoas que participarem dos grupos de PCAF terão os mesmos "resultados". Há de se considerar inclusive o viés de seleção dos sujeitos, uma vez que é plausível imaginar que outras pessoas que começaram a frequentar o grupo e não perceberam "resultados", ou não gostaram do grupo, das demais pessoas do grupo, etc. podem ter deixado de frequentar o grupo ou terem uma assiduidade menor do que a que foi considerada como critério de inclusão (50\%).

Entre os pontos positivos deste trabalho está a atualidade da temática, inclusive em função da recente da reforma da previdência ${ }^{24}$. Entre as limitações do estudo, apontamos a não escuta de outros atores como os familiares das entrevistadas e a própria gestão dos serviços de saúde.

\section{Conclusão}

Para as participantes deste estudo, a vida na velhice tem proporcionado sentimentos e percepções ambivalentes: queda na qualidade de vida devido a doenças, solidão e falta de autonomia, mas os provimentos da aposentadoria permitiram autonomia financeira. Para elas participar de um grupo de PCAF na UBS proporcionou melhora do quadro clínico de saúde, redução de dores corporais, melhoras no sono e pertencimento social. Quanto à aposentadoria, referiram que a realidade foi diferente do que imaginaram, principalmente pela piora da condição física e clínica e pelos cuidados dedicados a outros membros da família.

Nossos resultados reforçam que os profissionais da saúde precisam ter uma boa compreensão das especificidades da velhice, entendendo-a como uma fase da vida em que muitas contradições são observadas, fugindo-se assim de simplismos que buscam atribuir a esta fase um sentido de "melhor" ou "pior" que outros momentos da vida. Ademais, no caso das mulheres que atualmente são idosas, é preciso considerar que estas viveram períodos de grandes transformações no Brasil, inclusive no papel social da mulher e no aumento da expectativa de vida. Portanto, buscar uma compreensão deste cenário e da vida das idosas que participam de grupos de PCAF é fundamental, inclusive para fugir de simplismos como a ideia de "vida na melhor idade". Reforça-se a importância de políticas públicas voltadas a esta população, como o fortalecimento da $\mathrm{AB}$ por meio de equipes multiprofissionais que visem práticas de prevenção e promoção da saúde como as PCAF. 


\section{Conflito de interesse}

Os autores declaram não haver conflito de interesses.

\section{Contribuição dos autores}

Pimentel JO, coletou os dados, transcreveu as entrevistas, analisou os dados e escreveu o artigo. Loch MR, Orientou todas as etapas da pesquisa e realizou a revisão final do artigo.

\section{Referências}

1. Marra AV, Brito VGP, Oliveira MRCT, Dias BOSV. Imaginário, Subjetividade e Aposentadoria Feminina. BBR. 2011;8(2):119-37.

2. Instituto Brasileiro de Geografia e Estatística (IBGE). "Agência IBGE Notícias. Número de idosos cresce 18\% em 5 anos e ultrapassa 30 milhões em 2017". [Citado em 2020 out 01]. Disponível em: < https://agenciadenoticias.ibge.gov.br/ agencia-noticias/2012-agencia-de-noticias/noticias/20980numero-de-idosos-cresce-18-em-5-anos-e-ultrapassa-30milhoes-em-2017.

3. Fernandes MGM, Garcia LG. O Sentido da Velhice para Homens e Mulheres Idosos. Saúde Soc. 2010;19(4):771-83.

4. Mari FR, Alves GG, Aerts DRGC, Camara S. O processo de envelhecimento e a saúde: o que pensam as pessoas de meia-idade sobre o tema. Rev. Bras. Geriatr. Gerontol. 2016;19(1):35-44.

5. Beltrão KI, Alves JED. A reversão do hiato de gênero na educação brasileira no século XX. Cad Pesqui. 2009;39(136):125-56.

6. Brasil. Ministério da Saúde. Secretaria de Atenção à Saúde. Departamento de Ações Programáticas Estratégicas. Política Nacional de Atenção Integral à Saúde da Mulher: Princípios e Diretrizes. Brasília: Ministério da Saúde, 2004.

7. Brasil. Ministério da Saúde. Secretaria de Atenção à Saúde. Departamento de Ações Programáticas e Estratégicas. Área Técnica Saúde do Idoso. Atenção à Saúde da Pessoa Idosa e Envelhecimento. Brasília: Ministério da Saúde, 2010.

8. Brasil. Ministério da Saúde. Secretaria de Vigilância à Saúde. Secretaria de Atenção à Saúde. Política Nacional de Promoção da Saúde: PNaPS: revisão da Portaria MS/GM no 687, de 30 de março de 2006. Brasília: Ministério da Saúde, 2014.

9. Lee I-Min, Shiroma EJ, Kamada M, Bassett DR, Matthews $\mathrm{CE}$, Buring JE. Association of step volume and intensity with all-cause mortality in older women. JAMA Intern Med. 2019;179(8):1105-12.

10. Dumith SC, Maciel FV, Borchardt JL, Alam VS, Silveira FC, Paulitsch RG. Preditores e condições de saúde associados à prática de atividade física moderada e vigorosa em adultos e idosos no sul do Brasil. Rev Bras Epidemiol 2019;22: E190023.
11. Ciolac EG, Silva JMR, Vieira RP. Physical exercise as na immunomodulator of chronic diseases in aging. Journal of Physical Activity and Health. 2020;17(6):662-72.

12. Loch MR, Rodrigues CG, Teixeira DC. E os homens? e os que moram longe? e os mais jovens? ...? Perfil dos usuários de programas de atividade física oferecidos pelas unidades básicas de saúde de Londrina-PR. Rev. Bras. Ciênc. Esporte. 2013;35(4):947- 61.

13. Milech A, Häfele V, Siqueira FV. Perfil dos usuários do serviço de educação física em uma Unidade Básica de Saúde. Rev Bras Ativ Fis Saúde. 2018;23e0037.

14. Ramos LR, Malta DC, Gomes GAO, Bracco MM, Florindo AA, Mielke GI, et al. Prevalence of health promotion programs in primary health care units in Brazil. Rev Saúde Pública. 2014; 48(5): 837-44.

15. Becker LA, Gonçalves PB, Reis RS. Programas de promoção da atividade física no Sistema Único de Saúde brasileiro: revisão sistemática. Rev Bras Ativ Fis Saúde 2016;21(2): 110-22.

16. Loch MR, Knuth AG, Silva ICM, Guerra PH. As práticas corporais/atividade física nos 30 anos do Sistema Único de Saúde. Cien Saude Colet. 2018;23(10):3469.

17. Botton A, Cúnico SD, Strey MN. Diferenças de gênero no acesso aos serviços de saúde: problematizações necessárias. Mudanças. Psicologia da Saúde. 2017;25(1): 67-72.

18. Fraser MTD, Gondim SMG. Da fala do outro ao texto negociado: Discussões sobre a entrevista na pesquisa qualitativa. Paidéia. 2004;14(28):139-52.

19. Boni V, Quaresma SJ. Aprendendo a entrevistar: como fazer entrevistas em Ciências Sociais. R. Em Tese, revista do PPGSP da UFSC. 2005;2(1):68-80.

20. Bardin L. Análise de Conteúdo. Lisboa. Edições 70, 1979.

21. Carvalho FFB. Práticas corporais e atividades físicas na atenção básica do sistema único de saúde: ir além da prevenção das doenças crônicas não transmissíveis é necessário. Movimento. 2016;22(2):647-58.

22. Mizuno J, Brandani JZ, Deutsch S, Rossi F, Monteiro HL. Contribuições da prática do ioga na condição de saúde, atitudes e comportamentos de mulheres adultas e idosas. Movimento. 2018;24(3):947-60.

23. Ferreira RW, Caputo EL, Häfele CA, Jerônimo JS, Florindo AA, Knuth AG, et al. Acesso aos programas públicos de atividade física no Brasil: Pesquisa Nacional de Saúde, 2013. Cad Saúde Pública. 2019;35(2):1-13.

24. Oliveira SC, Machado CV, Hein AA. Reformas da Previdência Social no Chile: lições para o Brasil. Cad Saúde Pública. 2019;35(5):1-5.

Recebido: $25 / 03 / 2020$

Aprovado: 07/10/2020

Como citar este artigo:

Pimentel JO, Loch MR. "Melhor idade"? Será mesmo? A velhice segundo idosas participantes de um grupo de atividade física. Rev Bras Ativ Fís Saúde. 2020;25:e0140. DOI: 10.12820/rbafs.25e0140 